\title{
A lógica da diferença irredutível: a formação do psicanalista não é tarefa da universidade
}

\section{The logic of irreducible difference: the formation of the psychoanalyst is not the university task}

\section{La lógica de la diferencia irreductible: la formación del psicoanalista no es la tarea de la universidad}

\section{La logique de la différence irréductible: la formation du psychanalyste n'est pas une affaire de l'université}

\section{Luciano da Fonseca Elia*}

Universidade do Estado do Rio de Janeiro - UERJ, Rio de Janeiro, Rio de Janeiro, Brasil

\begin{abstract}
RESUMO
O autor discute as relações da psicanálise com a universidade, partindo da dissolução do tabu que consiste em sustentar o temor da aproximação entre ambas, do que resultou historicamente a aparente aversão das sociedades psicanalíticas à universidade, seu enquistamento em guetos iniciáticos que só produziram a mais despudorada academização dessas sociedades. Opõe esta movimento-tabu às novas relações que o ensino de Lacan introduziram, por distinguir os campos psicanalítico e universitário em termos de sua estrutura discursiva, permitindo que a aproximação entre esses campos deixe de ser temida, produzindo profícuas incidências da psicanálise na universidade, cujos eventuais efeitos de formação psicanalítica indefectivelmente esbarram na dimensão do impossível de fazer advir o psicanalista e sua autorização - função essencial da Escola de psicanálise no âmbito da universidade.
\end{abstract}

Palavras-chave: lógica, psicanalista, universidade, psicanálise.

\begin{abstract}
The author discusses the relationship between psychoanalysis and the university, based on the dissolution of the taboo that is to sustain the fear of rapprochement between both, than historically resulted in the apparent aversion of psychoanalytic societies to the university, his initiation encasement in ghettos that only produced the most shameless academic of these companies. Opposes this movement taboo to new relationships that teaching Lacan introduced, by distinguishing the psychoanalytic and university courses in terms of its discursive structure, allowing a closer relationship between these fields is no longer feared, producing fruitful psychoanalysis impact on university, whose possible effects of psychoanalytic training unfailingly bump in the dimension of impossible to come to the psychoanalyst and his authorization - essential function of psychoanalysis School - within the university.
\end{abstract}


Keywords: logic, psychoanalyst, university, psychoanalysis.

\begin{abstract}
RESUMEN
El autor analiza la relación entre el psicoanálisis y la universidad, a partir de la disolución del tabú que es mantener el temor de acercamiento entre ambos, que traducido históricamente en la aparente aversión de las sociedades psicoanalíticas a la universidad, su enquistamiento en guetos que sólo producen la más desvergonzada academización de estas empresas. Se opone a este movimiento tabú nuevas relaciones que la enseñanza de Lacan introdujo, distinguiendo los cursos psicoanalíticos y de la universidad en términos de su estructura discursiva, lo que permite una relación más estrecha entre estos campos ya no se teme, produciendo impacto psicoanálisis fructífera en la universidad, cuyos posibles efectos de la formación psicoanalítica chocan indefectiblemente en la dimensión de imposible llegar al psicoanalista y su autorización - la función esencial de la escuela de psicoanálisis - dentro de la universidad.
\end{abstract}

Palabras clave: lógica, psicoanalista, universidad, psicoanálisis.

\title{
RESUMÉ
}

L'auteur discute les rapports de la psychanalyse et de l'université à partir de la dissolution du tabou consistant à tenir la crainte de l'approche de ces deux champs, dont une aversion fut historiquement entrainée de la part des sociétés psychanalytiques envers l'université, de leur isolement en des ghettos initiatiques n'ayant produit que la plus impudente académisation de ces sociétés. L'auteur oppose ainsi ce mouvement-tabou aux nouveaux rapports que l'enseignement de Lacan ont introduits, d'avoir distingué le champ psychanalytique et l'universitaire en termes de leur structure discursive, permettant de ne plus craindre leur approche, et produisant de fructueuses incidences de la psychanalyse dans l'université, dont les éventuels effets de formation psychanalytique butent incontournablement sur la dimension de l'impossible de faire advenir le psychanalyste et son autorisation - fonction essentielle de l'École de psychanalyse - dans l'université.

Mots-clés: logique, psychanalyste, université, psychanalyse.

Tenho grande apreço pela universidade: pela instituição universitária em geral e pela Universidade do Estado do Rio de Janeiro, a UERJ, em particular. Do contrário, não teria como dar nenhuma sustentação ética ao fato de estar nela desde 1993, e de ter participado da fundação, em 1998, junto com colegas que muito prezo, do Programa de Pós-Graduação em Psicanálise do Instituto de Psicologia da UERJ, proponente e um dos co-organizadores do I Congresso Latinoamericano de Psicanálise na Universidade, o I CONLAPSA. Como psicanalista que se esforça por ser responsável, mesmo e mais ainda por só podermos nos responsabilizar pelo que ainda não podemos responder, seguindo uma posição discursiva lacaniana quanto à categoria de responsabilidade, não poderia sustentar essas atividades acadêmicas sem grande apreço por elas. Mas, se minha práxis sustenta a psicanálise na universidade, isso não me dispensa de 
destacar alguns fundamentos de saber a esta articulação da Psicanálise com a Universidade.

Em um breve recurso à História, direi que a instituição psicanalítica da era pós-freudiana e pré-lacaniana, a sociedade psicanalítica, tinha horror à universidade. Mas direi também que esse horror se sustentava de uma aparência: aquela que se baseia na perigosa vizinhança, sem distinção nem disjunção, entre um real não-interdito e o simbólico, e que por isso subsiste na constante ameaça de invasão do segundo pelo primeiro - base, segundo Alain Didier Weill, do que este autor chama de pensamento-tabu: "Algo que não exsiste no simbólico permanece em perigoso contato com ele: é o perigo de ser a causa de uma proibição dita tabu, que é radicalmente diferente do interdito, pois é fundamentalmente silenciosa" (DidierWeill, 1988, p. 7). Por não ter condições discursivas de distinguir a operação psicanalítica da universitária, a sociedade psicanalítica vive no tabu de permanente evitação da universidade, sua vizinha indistinta, e transpõe para o interior seu ensino a estrutura mais desavergonhadamente acadêmica: disciplinas, avaliações, periodizações letivas, duração pré-definida e até diploma, com direito também a eventuais cátedras, reservadas aos maxi-didatas.

$\mathrm{Na}$ prática, no ensino e na formação de orientação lacaniana a posição discursiva é inteiramente outra. A própria concepção de discurso, como estrutura sustentada na linguagem porém destituída de palavras e enunciações efetivas (Lacan, 1992) é que dará fundamento a que a psicanálise possa estar presente na universidade, incidir nela, operar no espaço acadêmico, nortear atividades de pesquisa, dialogar com a ciência como seu campo de procedência, tudo isso sem o tabu e o pesadelo do risco iminente de universitarização de sua práxis e de seu discurso.

Em um dos diálogos travados nos degraus do Panthéon, para onde foram no dia 13 de maio de 1970 (Lacan, 1992) depois de terem dado com a cara nas portas fechadas da Faculdade de Direito onde se dava o seminário naqueles anos de reboliço estudantil, Lacan diz que, se não houvesse a experiência analítica, ele não teria nem o direito nem a vontade de fazer o que faz, envolvendo o discurso filosófico para além de suas próprias condições de existência. O Sr. Z o interpela e diz, então, que isso transforma o discurso filosófico. Lacan responde, sem hesitar, que isso não o transforma, isso cria outro discurso. Mudamos de discurso, não transformamos um no outro. E na universidade, talvez mais do que em qualquer outro lugar, essas mudanças, alternâncias, saltos são talvez particularmente fecundos, desde que bem tolerados em vez de temidos ou até mesmo condenados por qualquer espécie de idealização, purismo ou castidade pseudo-psicanalítica.

Primeiro fundamento, portanto, da possibilidade de uma prática fecunda da psicanálise na universidade: as distinções discursivas 
introduzidas por Lacan. Não é à toa que foi com o movimento lacaniano que os psicanalistas começaram a sair de seus guetos institucionais, a ocupar espaço nas universidades, na saúde mental, nas instituições públicas de saúde, justiça, entre outras. E curiosamente esses mesmos analistas - digo isso em princípio, pois toda prática concreta apresenta amplo e diversificado espectro - são em geral os mais ciosos do rigor teórico de sua prática, e da clara distinção da psicanálise em face de seus campos conexos psicologia, psiquiatria, etc. Trabalhar na universidade ou no campo da saúde pública não reduz, portanto, o rigor da psicanálise, como parece estar demonstrado por estes efeitos produzidos pelo movimento lacaniano.

Tudo isso diz respeito à psicanálise aplicada, tal como conceituada por Lacan em oposição ao que, no mesmo ato (Lacan, 2003a) ele denominou de psicanálise pura. Contudo, mesmo considerando a aplicação da psicanálise a uma clínica ampliada (mais ampla do que a experiência psicanalítica estrita), a ser rigorosa esta aplicação, ela exigirá que suas condições discursivas sejam determinadas pelos eixos constitutivos do campo da psicanálise.

Assim, ainda que tenhamos definido um lugar fundamentado para a pesquisa em psicanálise, algumas questões não podem ser ignoradas. Por exemplo, em uma pesquisa psicanalítica que merece esse nome, será que podemos dizer que o pesquisador opera desde o lugar do psicanalista? Um psicanalista, referido a seu lugar, a rigor, pesquisa? Como ficam as condições estruturais de sua operação em uma pesquisa? Como fica a sua relação com o saber, a curiosidade científica, o desejo de saber? Será que podemos sustentar uma oposição do tipo: o psicanalista pratica a psicanálise rigorosa em seu consultório, na sua instituição psicanalítica ou escola, mas na universidade, onde faz pesquisa, ou no campo público em que eventualmente atua ele faz outra coisa, adaptada, relativizada? Não.

Penso que ficou definitivamente para trás a era em que se distinguia psicanálise de uma prática de base analítica acreditando com isso resguardar algum rigor quanto à primeira. Hoje, depois de todo o titânico empreendimento lacaniano, ou fazemos psicanálise ou fazemos psicanálise, seja onde for: consultório, ambulatório, enfermaria de hospital, presídio, serviço de saúde mental, etc., e seja em que nível for: clínica, pesquisa, transmissão, formação. O rigor terá que ser buscado e garantido de outro modo, pelas exigências do discurso que norteia qualquer práxis que responda pelo nome de psicanálise.

As coisas, entretanto, não se resolvem por isso de maneira simples. A rigor, quando se faz pesquisa em psicanálise, não é do lugar do analista que se opera, mas do analisante. $O$ pesquisador da psicanálise terá tanto mais chances de fazer com rigor sua pesquisa quanto mais próximo estiver do lugar do analisante, ao invés de 
pretender o lugar do analista, prestigioso só em aparência, impróprio na verdade para sua empreitada. Para isso proponho o nome de pesquisante, condensação de pesquisador com analisante. A partir deste lugar, ele não apenas poderá reconhecer em sua própria análise, portanto fora da universidade, no dispositivo analítico em intensão, o sintoma implicado em sua pesquisa (sempre o há) como, em outro sentido, e aqui no próprio espaço acadêmico em que realiza sua pesquisa, sempre como analisante, ele poderá desenvolver sua pesquisa, livre, por assim dizer, da confusão sintomática, exatamente porque, no mesmo eixo, mas em outro trilho, ele pôde analisar sua pesquisa. Novamente aqui as distinções e disjunções discursivas mostram suas benesses: espaços e dispositivos que, precisamente por se fazerem reger por uma mesma lógica (a lógica do discurso analítico), não se confundem, podem avizinhar-se sem riscos de uma imixão perniciosa.

Assim, não será pelo critério de uma distinção temática que discriminará grupos de temas que podem ou devem ser tomados como questões de pesquisa em dissertações de mestrado ou teses de doutorado e outro grupo de questões que se destinariam à escola de psicanálise por referirem-se à formação do analista que esses dois campos radicalmente distintos - o da universidade e o da escola de psicanálise - serão distinguidos. Um critério como este não atende ao princípio da contingência, próprio ao simbólico, e atém-se à dimensão do necessário, que é marca do imaginário, e neste sentido, é um critério, ele próprio, imaginário (este aspecto será mais detidamente tratado neste trabalho, adiante). A rigor, todo o qualquer tema em psicanálise poderá ser tomado como questão de pesquisa na universidade. Podemos conceber uma tese de doutorado sobre questões da psicanálise pura (garantia, autorização do analista, passe) por que não? A censura, neste caso, reintroduz o tabu: isso não pode ser tema de pesquisa, aquilo pode.

Entretanto, e ainda para demonstrar mais uma vez o quanto as coisas não cessam de esbarrar em novos pontos do impossível, tão logo supomos tê-las cernido simbólica e conceitualmente, vemos que é preciso nuançar o que acabamos de dizer, não para desdizê-lo (persistimos dizendo que não há nem pode haver temas-tabu para a pesquisa em psicanálise feita em ambiente universitário), mas para dizer que há temas e questões que não podem não ser formulados ou enunciados de um modo tal que impliquem o formulador em uma questão de análise e, portanto, de formação.

E aqui temos a formulação do impossível - não podemos não - que nos indica estarmos sob a incidência do real, o que é inteiramente diferente da proibição-tabu baseada no estatuto temático previamente definido. Então, poderíamos dizer: "Não toda" em vez de "nem toda" questão poderá ser tomada como tema de uma pesquisa em "psicanálise feita na universidade", indicando com isso a marca do 
não-todo, própria ao semi-dizer e ao discurso analítico, ao real e ao feminino, mas não própria ao que se pratica na universidade.

Se é o analisante que trabalha, estamos na lógica do discurso analítico, segundo a qual o sujeito dividido está no lugar do trabalho, do Outro do discurso. O que temos neste lugar no discurso universitário (discurso que não pode ser definido como aquele que vige na universidade como um lugar institucional e social, já que este lugar pode comportar a circulação e a incidência de diferentes discursos)? Temos o objeto $a$, no lugar em que, como propõe Lacan (1985), está situado aquele que é escravizado neste discurso, o estudante (que por isso Lacan denomina de astudante). E o que ele faz ali, na posição de trabalho? Produz o sujeito dividido, que fica então no lugar da produção, lugar marcado pelo gozo em todo discurso, efeito da pregnância dos lugares do discurso do mestre nos demais discursos. E o sujeito produzido pelo estudante-escravo no discurso universitário não é outra coisa senão o ensinante, o docente, o professor, ou seja, nós mesmos, caso consintamos nas operações do discurso universitário quando estamos na universidade. Mas podemos fazer outra coisa: fazer incidir, operar 0 discurso psicanalítico na universidade. Que incidências pode ter o discurso analítico nesta prática, ao situar o sujeito não como produção mas como trabalho, como analisante, o nosso pesquisante?

Cabe neste ponto um assinalamento que me parece essencial: ao interrogar os efeitos do discurso psicanalítico no âmbito da Universidade, não estou propondo que este discurso opere de modo exclusivo ou mesmo prevalente no plano das atividades de pesquisa, ensino ou extensão que vem sendo cada vez mais realizadas na universidade por psicanalistas rigorosos em sua formação. Sabemos que os discursos não operam de modo exclusivo, e que mesmo em uma Escola de psicanálise, e poderíamos radicalizar a questão estendendo-a até mesmo ao âmbito da experiência psicanalítica em intensão - que se desenrola entre psicanalista e psicanalisante - não se opera exclusivamente no discurso psicanalítico. Mais ainda em uma universidade, em que os diferentes modos do discurso e portanto do laço social se estabelecem, se entrecruzam permanentemente. O que sustentamos é que, em determinadas condições, podem-se verificar os efeitos do discurso psicanalítico na universidade, e para isso é preciso que psicanalistas tenham decidido trabalhar na universidade sem abrirem mão de sua condição de psicanalistas e coloquem essas condições em operação, em sua prática, em seu ato.

Esta posição tem consequências na própria concepção metodológica do que seja uma pesquisa em psicanálise. Valorizo muito este significante método por considerar que ele é extremamente valioso na robustez que a psicanálise precisa demonstrar na sua relação com outros campos do saber, sobretudo com a ciência, a fim de manter 
sua posição de rigor tanto no plano conceitual quanto no de suas derivações clínicas.

Não podemos, como psicanalistas, desconhecer que a psicanálise entretém com a ordem social e civilizatória uma relação de tensão e irredutibilidade, que faz com que ela nunca venha a ser inteiramente absorvida pelas representações que a sociedade poderá fazer dela. Esta posição traduz-se no que Freud (1969c) formulou como malestar na civilização, que não se reduz ao mal-estar do sujeito em sua condição gregária e social derivado da renúncia pulsional que todo laço civilizado exige, mas pode ser pensado na relação do próprio corpus psicanalítico com a cultura, a sociedade, o estado e finalmente com a ciência - e portanto também com a universidade - relação que sempre será marcada por um impossível a simbolizar, a aceitar, a incluir.

Ora, sem um cuidado metodológico, a psicanálise será muito mais facilmente objeto de críticas, infundadas ou não, ou seja, que independem em larga medida de um maior ou menor entendimento do que seja a psicanálise, porquanto não são críticas justas ou rigorosas mas baseadas no rechaço irracional e de tempos em tempos chegarão ao franco enxovalhamento.

Este é precisamente o caso do nosso tempo. Na contemporaneidade, a própria ciência parece ter renunciado a qualquer forma de rigor, ou antes, parece ter atingido o ponto em que considera poder dispensar todo rigor metodológico, já que, pela via do puro poder que the confere sua aliança com o capitalismo e o capital, ela reina no espaço social, nas decisões do poder público estatal quando elabora suas políticas públicas (por exemplo, na área da saúde e saúde mental em particular) e para isso emite julgamentos inteiramente ideológicos, tendenciosos e sectários, sem nenhum rigor científico, que tem sido invariavelmente condenatórios da psicanálise considerada imprópria, não recomendável e "não consensual" para ser adotada em práticas públicas de saúde mental - como no caso do seu uso em serviços públicos destinados ao tratamento do autismo, na França, supostamente por não apresentar evidências verificáveis de eficácia, que são formuladas, no entanto, por critérios metodológicos inteiramente estranhos ao seu campo (que os tem, robustos) e determinados pelo campo política e economicamente hegemônico, que detém os interesses da mais rentável indústria de todo o mundo, a dos psicofármacos e seus mega laboratórios multinacionais, que determinam agendas de periódicos e portanto definem a direção da produção científica, editais de concursos de docentes nas universidades e portanto definem a direção da formação de pesquisadores, e assim por diante.

A discussão metodológica parece-nos, assim, cada vez mais imperiosa, a fim de apontar as distorções pelas quais passam incessantemente os processos políticos da ciência e do Estado 
contemporâneo, com imediatas e eficazes consequências na sociedade através dos meios de comunicação (em que programas de televisão e revistas hebdomadárias de "informação" vem funcionando como instrumentos auxiliares de "periódicos científicos").

Além dessa dimensão política de batalha contra a ideologização e em favor do retorno do rigor científico em tempos nos quais a própria Epistemologia em sua função essencialmente crítica vem sendo dizimada na "comunidade científica internacional", a categoria de método vem sendo muitas vezes impropriamente substituído pela de ética. Há, indiscutivelmente, uma etificação da psicanálise (Cf. Allouch, 1997) que em nada ajuda no combate contra a ideologia nutrida pela associação da falsa ciência contemporânea com 0 capitalismo. Há também, indiscutivelmente, uma dimensão ética na experiência psicanalítica, uma Ética da psicanálise, e o próprio Lacan assim denominou um de seus seminários anuais (Lacan, 1988). Mas esta dimensão não deve sobrepor-se à discussão metodológica, fragilizando o discurso psicanalítico na afirmação de sua posição perante a ciência, o estado e a sociedade.

Do ponto de vista metodológico, a psicanálise é derivada da ciência, em todos os seus pontos, como bem demonstrou Lacan no que veio a ser conhecido como seu Doutrinal de ciência, denominação dada por Jean-Claude Milner ao capítulo central de sua magistral $A$ obra clara (Milner, 1996) e que retoma as teses desenvolvidas por Lacan em $A$ ciência e a verdade (Lacan, 1998c). Segundo essas teses, esta derivação remonta à fundação da Ciência - com " $\mathrm{C}$ " maiúsculo por dizer respeito a um corte maior, tal como proposto por Alexandre Koyré (2006) - que cria a própria ciência como tal, moderna e clássica, que coincide com o surgimento da Física Moderna no século XVII, com Galileu e depois Newton - e não às ciências humanas que só vieram a ser criadas no século XIX.

A psicanálise é científica de origem e nascença, mas não se mantém no espaço da ciência por ter nele reinserido o que a ciência, em seu ato de fundação, excluiu - o sujeito - que retorna como sujeito do inconsciente, campo este que mantém com a palavra ciência importantes relações, e Lacan assinalará em $O$ avesso da psicanálise (1992) que psicanálise e ciência têm um tronco comum, situado no discurso do mestre como o lugar da verdade no qual, neste discurso, figura justamente o sujeito dividido do inconsciente - que a ciência elide, mas que the retorna, de tempos em tempos, o que faz com que os verdadeiros cientistas jamais consigam derrubar as teses freudianas.

O sujeito do inconsciente vai, em determinado ponto de sua abordagem pelo método (inicialmente científico, em todo o seu rigor) de Freud, colocar em cena, pelo que se tornou conhecido através do termo de transferência, a sua dimensão não de forma anódina denominada de demoníaca (Freud, 1969b), posto que nela é 
propriamente de um demônio que se trata, e neste ponto os recursos do método científico revelam-se inócuos e inoperantes. Para fazer face a este demônio foi preciso inventar um novo método, o método psicanalítico, derivado da ciência mas não mais circunscrito a seus domínios, que ele precisou extravasar, transbordar, não sem desgosto por parte de seu criador, Freud, que teria preferido de bom grado permanecer no terreno científico, sua pátria de origem e formação, caso isso tivesse sido possível. Mas não foi. E foi preciso criar uma nova função, a do psicanalista, que não cabe inteiramente da função do cientista, razão pela qual a pesquisa em psicanálise não pode manter-se nos mesmos padrões metodológicos tradicionais da ciência, sob pena de, optando por ser uma "pesquisa (inteiramente) científica", cessar de ser uma pesquisa psicanalítica.

Será possível, por exemplo, do ponto de vista metodológico, fazer pesquisa em psicanálise prescindindo-se da transferência? Podem-se adotar os métodos de "pesquisa-ação", fazer uso do "observador participante" ou das mesclas metodológicas denominadas "quali/quanti"? Poderão ser utilizados questionários dirigidos, nos quais é a informação dada pelo pensamento consciente do "entrevistado" que norteará o dizer? Em outro sentido, o da verificação de evidências de eficácia, seria aplicável em psicanálise o método denominado "duplo cego", randomizado, no qual nem pesquisador nem sujeito da pesquisa podem ter conhecimento do que método está sendo aplicado, a fim de supostamente produzir evidências de eficácia "livres" das intenções de ambos? No campo de uma pretensa "ética da pesquisa", poderemos "explicar" nosso método aos sujeitos da pesquisa, a fim de que eles deem seu "consentimento" dito "livre e esclarecido", em um zelo pseudoético que confunde ética com um sentido de liberdade forjado na mais anglicana ideologia individualista?

Ou será que precisaremos sustentar, sem rodeios ou cerimônias, que toda pesquisa que se pretender psicanalítica terá que seguir as coordenadas do dispositivo clínico da psicanálise? E aqui reencontramos a máxima freudiana segundo a qual "a psicanálise faz em seu favor a reivindicação de que, em sua execução, tratamento e investigação coincidem" (Freud, 1969a). Esta frase de Freud deve ser tomada em um alcance bem maior do que aquele que habitualmente se lhe confere: não se trata apenas de uma íntima relação entre pesquisa e clínica, mas uma coextensividade, uma coincidência propriamente dita entre ambas, e se extrairmos disso uma consequência metodológica, concluiremos que a pesquisa precisará assumir as formas do dispositivo clínico.

Isto significa que, se quisermos empreender uma pesquisa em psicanálise sobre algum aspecto, fator ou recorte de uma problemática envolvendo necessariamente a experiência do sujeito, deveremos tratá-lo, tomá-lo no dispositivo clínico freudiano, que é 
único, e que é ao mesmo tempo de tratamento e de pesquisa, ambos clínicos. Não existe em psicanálise um método clínico de tratamento e um método de pesquisa, eles são um só e mesmo método.

A esta unicidade do método corresponde a mais completa diversidade de objetos - não deve existir veto ao que quer que seja que se possa tomar como objeto de investigação, e esta postura é rigorosamente sintônica com a metodologia da ciência. E à unicidade de método e diversidade do objeto a ciência rigorosa acrescenta a dimensão da pluralidade metodológica, ou seja, desde que haja rigor e consistência metodológica (e não ditadura ideológica movida por interesses estranhos à ciência) não é conveniente nem salutar ao espírito científico (Cf. Bachelard, 2011) decidir qual método é aceitável e qual(is) não é(são) pela ciência, como se faz hoje, de modo epistemologicamente fraudulento, em nome de uma hegemonia exclusivamente determinada por interesses econômicos, ideológicos e políticos que, se não são elimináveis de nenhuma prática humana, nem por isso podem ser hegemônicos ou reinar imperturbáveis, sem críticas, restrições ou limites, como se verifica hoje na dita "comunidade científica internacional", regida pelos métodos "baseados em evidências" que, no campo da saúde e das práticas "psi", compõem a chamada medicina do comportamento, associação da neurociências com a psicologia cognitivo-comportamental.

Ora, a ciência rigorosa reconhece, em termos da pluralidade metodológica, pelo menos seis sistemas metodológicos distintos, todos rigorosos, com especificidades metodológicas e modos de validação que Ihes são específicos, dentre os quais citamos, em primeiro lugar, o próprio método científico de inspiração galileana, chamado método hipotético-dedutivo, brilhantemente descrito por Gaston Bachelard (1977) consideravelmente distinto do que hoje se apresenta como método da ciência contemporânea, que afirma não importa o quê como necessário, como engendrado por petições de princípio, a priori, que não cessam de se escrever, sem nenhum respeito pela contingência que caracteriza o método verdadeiramente científico, pela fórmula cessa de não se escrever, segundo a qual o real é tratado pelo simbólico e não é como é por nenhuma necessidade a priori, mas poderia ser infinitamente diverso do que é, cabendo a ciência tornar inteligível a lógica e a gramática através das quais o real é como é (Cf. Milner, 1996).

Mas podemos incluir na série de métodos, todos mutuamente reconhecidos como sérios e rigorosos e devendo coexistir no universo científico: o método psicanalítico, de que tratamos especificamente aqui, e que caracterizamos acima em suas coordenadas gerais; o método fenomenológico, criado por Husserl como produtor da Fenomenologia como uma ciência exata (Husserl, 1950), e sobre o qual Merleau-Ponty dirá, no seu excelente Prefácio à Fenomenologia da percepção: "a fenomenologia só é acessível ao método 
fenomenológico" (Merleau-Ponty, 1999, p. 12); o método estruturalista, cujo expoente maior que aqui citamos é Lévi-Strauss (Lévi-Strauss, 2008); o método dialético (Hegel) e o materialismo histórico (Marx), sistematizado de forma monumental na Crítica da razão dialética, obra precedida por uma outra, de menor porte, intitulada Questões de método (Sartre, 1960); e, finalmente, o método genealógico, o mais recente, criado por Michel Foucault, distinto de qualquer outro dos citados (Foucault, 1979).

Voltando ao método psicanalítico, cabe assinalar que, resguardada a unicidade do método (clínica e pesquisa), é preciso introduzir uma importante diferença entre as démarches "empreender uma psicanálise" e "empreender uma pesquisa em psicanálise", diferença que incidirá nas relações aqui problematizadas entre a psicanálise e sua Escola e Universidade: quando alçado à dimensão de pesquisa, a produção de saber ocupará outro lugar no método, o lugar do que é visado, lugar que ele absolutamente não tem para o psicanalista: este não quer saber quando agencia o seu discurso, e o desejo do psicanalista não visa o saber, mas "a diferença absoluta, aquela que intervém quando, confrontado com o significante do seu desejo, o sujeito vem pela primeira vez em posição de se assujeitar a ele" (Lacan, 1985, p. 260).

Retornamos, assim, ao discurso psicanalítico tal como formulado por Lacan e suas incidências respectivas na universidade e na Escola de psicanálise. Certamente que essas incidências não são as mesmas. Em nenhum caso, na universidade, tratar-se-á de verificar o analista, de interrogar o que é um psicanalista, e de saber se há ou houve psicanalista em determinado ato. A universidade não tem este mandato, não tem e não deveria ter as condições discursivas para isso, não se constitui como um dispositivo capaz de fazer esta verificação. Esta é uma tarefa da escola de psicanálise: criar condições de formação, autorização e verificação do psicanalista, e da pergunta fundamental - "o que é um psicanalista?"

Na Proposição 9 de outubro de 1967 sobre o psicanalista da Escola, Lacan afirma: "O analista se autoriza por ele mesmo" (Lacan, 2003b, p. 258). Mas este é um princípio do psicanalista da Escola, formulado logo de saída nesta Proposição, e não do psicanalista isolado - aporia paradoxal que deveria, no mínimo, nos exigir algum trabalho antes de liberarmos o psicanalista por ele mesmo autorizado de qualquer constrangimento derivado da existência do laço em que consiste a Escola.

Como se sabe, o texto da Proposição teve mais de uma versão escrita e publicada, tendo inclusive sido lido por Lacan em uma reunião de psicanalistas por ele convidados a ouvi-la nos primeiros dias de outubro de 1967. Existe uma primeira versão da Proposição, publicada no anexo do volume Outros Escritos, o mesmo em que, aliás, encontra-se a chamada versão definitiva da Proposição, e é 
apenas nesta versão primeira que Lacan (2003c) situa a questão dos gradus - AME (analista membro da Escola) e $A E$ (analista da Escola) - nos dois níveis de seu famoso grafo do desejo, construído nos final dos anos 50, nos Seminários 5 - As formações do inconsciente, dos anos 1957/58 (Lacan, 1998a) e 6 - O desejo e sua interpretação, dos anos 1958/59 (Lacan, 2016) e no escrito que lhes corresponde Subversão do sujeito e dialética do desejo no inconsciente freudiano, (Lacan, 1998b).

O interesse desta articulação dos dois níveis dos gradus com os dois níveis do grafo do desejo é que ela permite formular duas perguntas distintas e muito específicas para cada um dos gradus: em relação ao $A M E$, que envolve a questão da autorização e resulta na denominação, feita pela Escola, dos analistas membros da escola (AME), a pergunta é: "quais são os psicanalistas desta escola?", situável no primeiro andar do grafo do desejo, na posição $s(A)-$ significado dado ao Outro - que designa o lugar do sintoma: os AME que uma escola nomeia, cuja formação assegura (garantia) como derivada do que esta Escola promove funcionam como um sintoma desta Escola.

Mas a outra pergunta: "- o que é um psicanalista", que não admite resposta formal tal como a nomeação de psicanalistas e a garantia por parte da escola, por exemplo, concerne ao $A E$ (analista da Escola), e se situa na posição correspondente àquela que, no primeiro nível do grafo, é ocupada por $s(A)$, mas desta vez no segundo, o nível da cadeia transversal estruturada no inconsciente, no ponto em que Lacan escreve o matema, lugar que, como seu correspondente no primeiro nível do grafo, lado esquerdo da curva retroativa, em seu trecho descendente que o grafo traça, destina-se à mensagem, enquanto que, do lado direito, ascendente no seu percurso, situam-se as duas notações do lugar do código. Como conceber uma mensagem sem significado, matemicamente formalizada, e, portanto, formulada em termos literais, porém em termos puramente significantes? Pois é exatamente disso que se trata na interrogação própria ao $A E$ - o que é um psicanalista? - interrogação que não admite respostas semânticas, de conteúdo conceitual, e tampouco pode ser formulada no âmbito acadêmico.

Esta é, na verdade, a principal questão de uma escola, e, por sua condição estritamente literal, não pode ser respondida ou articulada em palavras, mas exige que aquele que a toma em seu encargo, 0 $A E$, a tome em ato, relançando-a permanentemente, tornando-se, no dizer de Lacan, analista de sua própria experiência - e portanto também a própria Escola. Esta pergunta implica a experiência do passe, dispositivo criado por Lacan de verificação da passagem de analisante a analista, e é justamente esta dimensão da experiência do psicanalista que não tem lugar na Universidade, e constitui uma questão exclusiva da Escola de Psicanálise. 
Na versão definitiva da Proposição, finalmente publicada, Lacan afirma: "Há um real em jogo na própria formação do psicanalista. Sustentamos que as sociedades existentes se fundam sobre este real". E logo adiante: "... é fato patente que este real provoque seu próprio desconhecimento, e até mesmo que produza sua negação sistemática" (Lacan, 2003b, p. 249). A sociedade psicanalítica se sustenta no desconhecimento e na negação sistemática do real em jogo na formação do psicanalista, sobre o qual ela, assim, se funda. $\mathrm{Na}$ Escola de Lacan, este real não é menos ex-sistente, interdito, mas podemos dizer que uma escola consiste no movimento permanente e insistente de não negá-lo nem desconhecê-lo, mas de levá-lo em conta.

Já a universidade, como lugar da pluralidade de saberes, práticas e discursos, não tem a menor condição, possibilidade e nem mesmo desejo ou vocação para prestar-se como dispositivo de verificação de algo que diz respeito tão puramente (alusão à psicanálise pura), tão restritivamente, à experiência psicanalítica.

De modo articulado ao seu pluralismo, a universidade é UNI, tem aspiração universal. É uni e é pluri, unipluri, visa a totalidade dos saberes, a reunião do todo. A universidade segue a lógica do Um plural, do masculino. Em psicanálise, dizemos que não há o universo do discurso porque não há uma psicanálise universal, nem universitária.

A psicanálise, não-toda, não é sem relação com a lógica do todo, do para todos, do pai, do Um e do homem. Mas ela introduz o não-todo do feminino, ali onde vige o todo do masculino. Há, na relação psicanálise-universidade, algo da relação entre os sexos, algo, portanto, da relação que não há. Não há relação psicanalíticouniversitária, tanto quanto não há relação sexual. Acho que é justamente por isso que elas podem articular-se, que podemos fazer viver, fecunda e frutuosamente, a psicanálise na universidade.

\section{Referências}

Allouch, J. (1997). A etificação da psicanálise, Rio de Janeiro: Companhia de Freud.

Bachelard, G. (1977). O racionalismo aplicado (1949), Rio de Janeiro: Zahar Editores. (Trabalho original publicado em 1949).

Bachelard, G. (2011). La formation de l'esprit scientifique. Paris: Vrin. (Trabalho original publicado em 1938).

Didier-Weill, A. (1988). Inconsciente freudiano e transmissão da psicanálise. Coleção Transmissão da Psicanálise, no 6 . Rio de Janeiro: Jorge Zahar Editor.

Foucault, M. (1979). Microfísica do poder. Rio de Janeiro: Graal Editora. 
Freud, S. (1969a). Recomendações aos médicos que praticam a psicanálise. In Freud, S. Edição Standard Brasileira das Obras Psicológicas Completas de Sigmund Freud, (pp. 149-163), Vol. XII. Rio de Janeiro, Imago Editora. (Trabalho original publicado em 1912).

Freud, S. (1969b). Observações sobre o amor transferencial. In Freud, S. Edição Standard Brasileira das Obras Psicológicas Completas de Sigmund Freud, Vol. XII. (pp. 208- 221). Rio de Janeiro, Imago Editora. (Trabalho original publicado em 1915).

Freud, S. (1969c). Mal-estar na civilização. In Freud, S. Edição Standard Brasileira das Obras Psicológicas Completas de Sigmund Freud, Vol. XXI. (pp. 81-178). Rio de Janeiro, Imago Editora. (Trabalho original publicado em 1930).

Husserl, E. (1950). Idées directives pour une phénoménologie pure. Paris: Éditions Gallimard. (Trabalho original publicado em 1913).

Koyré, A. (2006). Do mundo fechado ao universo infinito. Rio de Janeiro: Forense Universitária. (Trabalho original publicado em 1958).

Lacan, J. (1985). O seminário, livro 11: Os quatro conceitos fundamentais da psicanálise. Rio de Janeiro: Jorge Zahar Editor. (Seminário ministrado em 1963/1964).

Lacan, J. (1988). O seminário, livro 7: A ética da psicanálise. Rio de Janeiro: Jorge Zahar Editor. (Seminário ministrado em 1959/1960).

Lacan, J. (1992). Conversa nos degraus do Panteão. In Lacan, J. $O$ Seminário, livro XVII: o avesso da psicanálise. (pp.135-141). Rio de Janeiro: Jorge Zahar Editor. (Seminário ministrado em 1969/1970).

Lacan, J. (1998a). O seminário, livro 5: As formações do inconsciente. Rio de Janeiro: Jorge Zahar Editor. (Seminário ministrado em 1957/1958).

Lacan, J. (1998b). Subversão do sujeito e dialética do desejo no inconsciente freudiano. In Lacan, J. Escritos. (pp. 807-842). Rio de Janeiro: Jorge Zahar Editor. (Trabalho original publicado em 1960).

Lacan, J. (1998c). A ciência e a verdade. In Lacan, J. Escritos. (pp. 869-892). Rio de Janeiro: Jorge Zahar Editor. (Trabalho original publicado em 1966).

Lacan, J. (2003a). Ato de fundação (da École Française de Psychanalyse - EFP, posteriormente renomeada École Freudienne de Paris), 21 de junho de 1964. In Lacan, J. Outros Escritos. (pp. 235-239). Rio de Janeiro: Jorge Zahar Editor. (Trabalho original de 1964).

Lacan, J. (2003b). Proposição 9 de outubro de 1967 sobre o psicanalista da Escola. In Lacan, J. Outros Escritos. (pp. 248- 
264.). Rio de Janeiro: Jorge Zahar Editor. (Trabalho original de 1967).

Lacan, J. (2003c). Proposição 9 de outubro de 1967 sobre o psicanalista da Escola - primeira versão. In Lacan, J. Outros Escritos, (pp. 570-586). Rio de Janeiro: Jorge Zahar Editor. (Trabalho original publicado em 1978).

Lacan, J. (2016). O seminário, livro 6: O desejo e sua interpretação. Rio de Janeiro: Jorge Zahar Editor. (Seminário ministrado em 1958/1959).

Lévi-Strauss, C. (2008). Antropologia estrutural. São Paulo: Cosac Naify. (Trabalho original publicado em 1958).

Merleau-Ponty, M. (1999). Fenomenologia da percepção. Martins Fontes. (Trabalho original publicado em 1945).

Milner, J. C. (1996). A obra clara - Lacan, a ciência, a filosofia. Rio de Janeiro: Jorge Zahar Ed.

Sartre, J. P. (1960). Critique de la raison dialectique. (precedido de Questions de méthode, 1957), Paris: Éditions Gallimard.

\section{Endereço para correspondência}

Luciano da Fonseca Elia

Universidade do Estado do Rio de Janeiro - UERJ

Instituto de Psicologia

Rua São Francisco Xavier, 524, 10 andar, CEP 20550-900, Rio de Janeiro - RJ, Brasil

Endereço eletrônico: lucianoelia@uol.com.br

Recebido em: 10/01/2015

Reformulado em: 14/06/2017

Aprovado em: 20/06/2017

\section{Notas}

* Professor Titular do Instituto de Psicologia da Universidade do Estado do Rio de Janeiro, Programa de Pós-graduação em Psicanálise. Psicanalista. Membro do Laço Analítico, Escola de Psicanálise. Supervisor clínico-territorial da rede municipal de saúde mental do Rio de Janeiro e da cidade de Vitória (ES). Rio de Janeiro, RJ, Brasil. 